\title{
Article
}

\section{SARS-CoV-2 Seroprevalence Post-First Wave among Primary Care Physicians in Catania (Italy)}

\author{
Caterina Ledda ${ }^{1, *(\mathbb{D}}$, Flavia Carrasi ${ }^{1}$, Maria Teresa Longombardo ${ }^{2}$, Gianluca Paravizzini ${ }^{2}$ and Venerando Rapisarda ${ }^{1}$ (D) \\ 1 Occupational Medicine, Department of Clinical and Experimental Medicine, University of Catania, \\ 95100 Catania, Italy; L98002367@studium.unict.it (F.C.); vrapisarda@unict.it (V.R.) \\ 2 Clinical Laboratories "Girlando and Paravizzini", 95100 Catania, Italy; \\ m.longombardo@girlandoeparavizzini.com (M.T.L.); gianluca@paravizzini.net (G.P.) \\ * Correspondence: cledda@unict.it; Tel./Fax: +39-095-3782049
}

Citation: Ledda, C.; Carrasi, F.; Longombardo, M.T.; Paravizzini, G.; Rapisarda, V. SARS-CoV-2

Seroprevalence Post-First Wave among Primary Care Physicians in Catania (Italy). Trop. Med. Infect. Dis. 2021, 6, 21. https://doi.org/10.3390/ tropicalmed6010021

Received: 9 January 2021

Accepted: 7 February 2021

Published: 9 February 2021

Publisher's Note: MDPI stays neutral with regard to jurisdictional claims in published maps and institutional affiliations.

Copyright: (c) 2021 by the authors. Licensee MDPI, Basel, Switzerland. This article is an open access article distributed under the terms and conditions of the Creative Commons Attribution (CC BY) license (https:// creativecommons.org/licenses/by/ $4.0 /)$.

\begin{abstract}
Family physicians or pediatricians and general practitioners (GPs) work in non-hospital settings. GPs usually visit many patients, frequently at their homes, with low potential, if any, to control the work setting. Particularly during the initial phases of the COVID-19 outbreak, they were not informed about the occurrence of SARS-CoV-2-infected patients, with inadequate information regarding the risk, a lack of suitable protective measures and, in some cases, deficient or poor accessibility to personal protective equipment (PPE). During the first wave of COVID-19, primary care physicians were on the front line and isolated the first cases of the disease. The present study aims to estimate the seroprevalence of SARS-CoV-2 in a cohort of 133 GPs working in Catania (Italy) after the first wave of COVID-19. Serological analysis revealed a low seroprevalence (3\%) among GPs. The low seroprevalence highlighted in the results can be attributed to correct management of patients by GPs in the first wave. It is now hoped that mass vaccination, combined with appropriate behavior and use of PPE, can help further reduce the risk of COVID-19 disease.
\end{abstract}

Keywords: COVID-19; healthcare worker; healthcare personnel; SARS-CoV-2; general practitioners; medical doctor

\section{Introduction}

The novel coronavirus (SARS-CoV-2), the causative agent of Corona Virus Disease2019 (COVID-19), is the most severe global public health emergency of the twenty-first century [1].

The disease, which appeared in Wuhan, China, in December 2019, quickly spread across continents and was declared a pandemic by the World Health Organization (WHO) on 11 March 2020 [2].

At 5 February 2021, SARS-CoV-2 has infected over 104,000,000 persons and caused over 2,200,000 deaths globally [2].

Current information suggests that, in community settings, person-to-person transmission most commonly occurs via the respiratory droplets of the infected individual (through coughing, sneezing, talking, etc.), close interaction with the infected person, or self-delivery of the microorganism to the eyes, nose, or mouth via SARS-CoV-2 contaminated hands [3].

In health care scenarios, in addition to respiratory droplet-borne or contact-borne transmission, airborne transmission can also occur via aerosol-generating operations [3].

SARS-CoV-2 is highly transmissible, and health care workers (HCWs) have been occupied with the important risk of providing care to supposed or confirmed COVID-19 cases. Some reports have shown that numerous HCWs have contracted COVID-19 in health care settings globally [4-8].

The WHO, the Center for Disease Control and Prevention (CDC), and the European Centre for Disease Prevention and Control (ECDC) issued procedures for COVID-19 
management that endorse safety protocols for HCWs, such as using appropriate personal protective equipment (PPE).

Nevertheless, because the suggested infection control protections have not been adequate to prevent the spread of the SARS-CoV-2 infection among HCWs, unrecognized risk factors may contribute to the transmission of viruses in hospitals [4-8].

However, not all healthcare is provided in a hospital setting. In particular, family physicians or pediatricians and general practitioners (GPs) work in a setting away from the hospital.

GPs usually visit numerous patients, frequently at their homes, with low potential, if any, to control the work setting. Particularly during the initial phases of the COVID-19 outbreak, GPs were not informed of the occurrence of SARS-CoV-2-infected patients, with inadequate information about the risk, a lack of suitable protective measures and, in some cases, deficient or poor accessibility to PPE [9].

Modenese and Gobba reported that 44\% of the COVID-19 related deaths among Italian physicians were GPs [10].

In Italy, the first wave started at the end of January 2020 and in March, the government implemented a series of restrictive measures. On March 5th, all schools and universities in Italy locked their buildings to scholars. From 8 March to 4 May, the population was forced to respect the lockdown.

In the province of Catania, 777 cases [11] of COVID-19 were reported until the end of June, that is, the period of the effect of the lockdown.

The present study aims to estimate the seroprevalence of SARS-CoV-2 in a cohort of GPs working in Catania (Italy) after the first wave of COVID-19.

\section{Materials and Methods}

In the province of Catania, there are approximately 1100 working GPs. From June to July 2020, GPs working in the province of Catania (Italy) were recruited in this study through contacts made via mail from a GP database obtained from the Medical Board.

The GPs who made themselves available to participate in the study were contacted by email and filled out an online form that included the registration of: personal and work data, number of patients with COVID-19, any previous diagnosis of COVID-19 through molecular swab, eventual close contact with cases of COVID-19, possible presence of symptoms of COVID-19 attributable to contact, presence of other pathologies.

Following the receipt of answers from the GPs, blood sampling sessions were organized, two at the University of Occupational Medicine, and four in the province. The collected serum was immediately taken to the laboratory and analyzed the same day.

Serological analysis was performed using The NovaLisa ${ }^{\circledR}$ SARS-CoV-2 IgG (NovaTec Immundiagnostics $\mathrm{GmbH}$, Dietzenbach, Germany) ELISA method. The aim of the test was the qualitative detection of IgG antibodies to SARS-CoV-2 virus in human serum.

Informed consent was obtained from all GPs. The present study was approved by the ethics committee of Catania University Hospital (n. 54/2020).

Data were analyzed with the software SPSS 22.0 (SPSS Inc., Chicago, IL, USA) for Windows. Descriptive analyses were performed using frequency percentages and mean and standard deviation.

\section{Results}

An invitation email was sent to 170 GPs. A total of 133 elected to participate in the study (response rate: 78\%). The characteristics of the participating GPs are detailed in Table 1.

As reported in Table 1, three GPs had a COVID-19 diagnosis. SARS-CoV-2 antibodies were detected in 4 of $133(3 \%)$ of GPs, and $2(2 \%)$ had a "borderline" result. Table 2 reports the seroprevalence results after ELISA analysis. 
Table 1. Characteristics of participating general practitioners (GPs).

\begin{tabular}{cc}
\hline Variables & Results \\
\hline Gender (Male; n, \%) & $62(47 \%)$ \\
Age (Mean \pm SD) & $55.65 \pm 11.24$ \\
Working seniority (Mean \pm SD) & $15.14 \pm 13.62$ \\
Patients & $994.44 \pm 358.33$ \\
GPs with COVID-19 patients (n., \%) & $51(38 \%)$ \\
GPs who had swabbed for SARS-CoV-2 RT detection (n., \%) & $21(16 \%)$ \\
GPs with COVID-19 diagnosis & $3(2 \%)$ \\
GPs with close contacts with cases of COVID-19 (n., \%) & $78(59 \%)$ \\
Probable cases & $21(20 \%)$ \\
Presence of COVID-19 symptoms (n., \%) & \\
Hyposmia * (n., \%) & $4(3 \%)$ \\
Ageusia * (n., \%) & $2(2 \%)$ \\
Fever > 37.5 ${ }^{\circ}$ * (n., \%) & $23(23 \%)$ \\
Fatigue * (n., \%) & $65(49 \%)$ \\
Muscle aches * (n., \%) & $52(52 \%)$ \\
Sore throat * (n., \%) & $50(50 \%)$ \\
Dry cough * (n., \%) & $48(36 \%)$ \\
Nasal congestion * (n., \%) & $41(31 \%)$ \\
Rhinorrhea * (n., \%) & $40(30 \%)$ \\
Dyspnea * (n., \%) & $9(7 \%)$ \\
Headache * (n., \%) & $53(40 \%)$ \\
Abdominal pain * (n., \%) & $23(17 \%)$ \\
\hline
\end{tabular}

${ }^{*}$ More than one answers was given.

Table 2. Seroprevalence of GPs.

\begin{tabular}{cc}
\hline Results & n. (\%) \\
\hline Negative & $127(95 \%)$ \\
Positive & $4(3 \%)$ \\
Borderline & $2(2 \%)$ \\
\hline
\end{tabular}

\section{Discussion}

The aim of this study was to assess the SARS-CoV-2 seroprevalence, after the first wave of the disease, among GPs working in Catania province (Italy). Probable cases, according to WHO criteria [12], were 21 (20\%). Serological analysis revealed a low seroprevalence (3\%) among GPs.

These low seroprevalence rates were found despite the treatment of 777 patients with COVID-19 infections during the first wave [11] period in which GPs worked with very few PPE available from the local health authority. Nevertheless, the degree of contagion was lower in GPs compared to HCWs in direct contact with COVID-19 patients in hospital settings. Other seroprevalence studies carried out among HCWs working in hospital report higher rates of prevalence: Belgium (12.6\%) [13], Spain (11.2\%) [14], Italy (14.4\%) [15], Sweden (19.1\%) [16], the United Kingdom (10.8-43.5\%) [13,17], and the United States of America (7.6-13.7\%) [18,19]. The differences in these rates may be due to differences in seroprevalence in the general population by May 2020: 8.0\% in Belgium, 5.5\% in Spain, 4.6\% in Italy, 3.7\% in Sweden, 5.1\% in the United Kingdom, and only 0.85\% in Germany [20].

A recent study on duration of SARS-CoV-2 antibody carried out by Lumley et al. [21] evidences that anti-spike IgG levels remained stably detected after a positive result in $94 \%$ of health care workers after 180 days, instead anti-nucleocapsid IgG levels rose to a peak at 24 and the mean estimated antibody half-life was 85 days. Ongoing longitudinal studies are required to track the long-term duration of antibody levels and their association with immunity to SARS-CoV-2 reinfection and evaluate these two IgG fractions for guide vaccination modalities. 
To date, no seroprevalence studies have been carried out among GPs by other research groups.

Due to the type of work and the shortage of PPE, GPs contracted the virus at the beginning of the spread of SARS-CoV-2. Subsequently, distancing rules were also adopted within clinics, and overnight stays and contact were avoided unless requested. Thus, contagion was able to be reduced.

It is has been found that rigorous use of appropriate PPE by HCWs when providing direct care of all patients efficiently prevents COVID-19 transmission [22,23]. Moreover, a study carried out by Brehm underlines that mindfulness of COVID-19 is crucial even when suitable PPE is used.

Our results are in line with an investigation carried out by Arons [24], which proved that pre-symptomatic patients play a crucial role in the spread of SARS-CoV-2 associated with both community and healthcare facilities.

It is important to finalize strategies and procedures to prevent SARS-CoV-2 infection among GPs, for example, specific guidelines for GPs to safely guarantee care for patients during the spread of COVID-19. Another input could be the introduction of telemedicine procedures to reduce direct contact with patients [10,25-27].

In conclusion, the low seroprevalence highlighted in these results can be attributed to correct management of patients by GPs during the first wave. It is now hoped that mass vaccination, in combination with appropriate behavior and use of PPE, can help further reduce the risk of COVID-19 disease.

Author Contributions: Conceptualization, C.L. and V.R.; methodology, G.P.; validation, C.L., V.R. and M.T.L.; formal analysis C.L. and M.T.L.; investigation, C.L.; data curation, C.L. and F.C.; writingoriginal draft preparation, F.C.; writing-review and editing, C.L.; supervision, V.R. All authors have read and agreed to the published version of the manuscript.

Funding: This research received no external funding.

Institutional Review Board Statement: The study was conducted according to the guidelines of the Declaration of Helsinki, and approved by the Ethics Committee of Catania 1 (n. 54/2020).

Informed Consent Statement: Informed consent was obtained from all subjects involved in the study.

Data Availability Statement: Data available on request due to privacy restrictions.

Conflicts of Interest: The authors declare no conflict of interest.

\section{References}

1. Vella, F.; Senia, P.; Ceccarelli, M.; Vitale, E.; Maltezou, H.; Taibi, R.; Lleshi, A.; Rullo, E.V.; Pellicano, G.F.; Rapisarda, V.; et al. Transmission mode associated with coronavirus disease 2019: A review. Eur. Rev. Med. Pharmacol. Sci. 2020, 24, 7889-7904.

2. Coronavirus Disease (COVID-2019) Situation Reports. Available online: https://www.who.int/emergencies/diseases/novelcoronavirus-2019/situation-reports (accessed on 5 February 2021).

3. Interim, U.S. Guidance for Risk Assessment and Work Restrictions for Healthcare Personnel with Potential Exposure to COVID19. Available online: https://www.cdc.gov/coronavirus/2019-ncov/hcp/guidance-risk-assesment-hcp.html (accessed on 9 January 2021).

4. Xiang, Y.; Jin, Y.; Wang, Y.; Zhang, Q.; Zhang, L.; Cheung, T. Tribute to health workers in china: A group of respectable population during the outbreak of the COVID-19. Int. J. Biol. Sci. 2020, 16, 1739-1740. [CrossRef]

5. Chou, R.; Dana, T.; Buckley, D.I.; Selph, S.; Fu, R.; Totten, A.M. Update alert: Epidemiology of and risk factors for coronavirus infection in health care workers. Ann. Intern. Med. 2020, 173, W46-W47. [CrossRef]

6. Reusken, C.B.; Buiting, A.; Bleeker-Rovers, C.; Diederen, B.; Hooiveld, M.; Friesema, I.; Koopmans, M.; Kortbeek, T.; Lutgens, S.P.M.; Meijer, A.; et al. Rapid assessment of regional SARS-CoV-2 community transmission through a convenience sample of healthcare workers, the netherlands, march 2020. Eurosurveillance 2020, 25, 2000334. [CrossRef]

7. Heinzerling, A.; Stuckey, M.J.; Scheuer, T.; Xu, K.; Perkins, K.M.; Resseger, H.; Magill, S.; Verani, J.R.; Jain, S.; Acosta, M.; et al. Transmission of COVID-19 to health care personnel during exposures to a hospitalized patient-solano county, california, february 2020. Morb. Mortal. Wkly Rep. 2020, 69, 472-476. [CrossRef] [PubMed]

8. Keeley, A.J.; Evans, C.; Colton, H.; Ankcorn, M.; Cope, A.; State, A.; Bennett, T.; Giri, P.; De Silva, T.I.; Raza, M. Roll-out of SARS-CoV-2 testing for healthcare workers at a large NHS foundation trust in the united kingdom, march 2020. Eurosurveillance 2020, 25, 000433. [CrossRef] [PubMed] 
9. Kamerow, D. Covid-19: Don't forget the impact on US family physicians. BMJ 2020, 368, m1260. [CrossRef] [PubMed]

10. Modenese, A.; Gobba, F. Increased Risk of COVID-19-Related Deaths among General Practitioners in Italy. Healthcare 2020, 8, 155. [CrossRef] [PubMed]

11. Covid 19-Ripartizione dei Contagiati per Provincia-21/06/2020 ore 17. Available online: http://www.salute.gov.it/imgs/C_17 _notizie_4922_1_file.pdf (accessed on 9 January 2021).

12. World Health Organization. Global Surveillance for COVID-19 Caused by Human Infection with COVID-19 Virus: Interim guidance, 20 March 2020; World Health Organization: Geneva, Switzerland, 2020. Available online: https://apps.who.int/iris/handle/10665/ 331506 (accessed on 5 February 2021).

13. Martin, C.; Montesinos, I.; Dauby, N.; Gilles, C.; Dahma, H.; Van Den Wijngaert, S.; De Wit, S.; Delforge, M.; Clumeck, N.; Vandenberg, O. Dynamics of SARS-CoV-2 RT-PCR positivity and seroprevalence among high-risk healthcare workers and hospital staff. J. Hosp. Infect. 2020, 106, 102-106. [CrossRef]

14. Garcia-Basteiro, A.L.; Moncunill, G.; Tortajada, M.; Vidal, M.; Guinovart, C.; Jiménez, A.; Santano, R.; Sanz, S.; Méndez, S.; Llupià, A.; et al. Seroprevalence of antibodies against SARS-CoV-2 among health care workers in a large spanish reference hospital. Nat. Commun. 2020, 11, 3500. [CrossRef]

15. Sotgiu, G.; Barassi, A.; Miozzo, M.; Saderi, L.; Piana, A.; Orfeo, N.; Colosio, C.; Felisati, G.; Davì, M.; Gerli, A.G.; et al. SARS-CoV-2 specific serological pattern in healthcare workers of an italian COVID-19 forefront hospital. BMC Pulm. Med. 2020, $20,203$. [CrossRef]

16. Rudberg, A.; Havervall, S.; Månberg, A.; Jernbom Falk, A.; Aguilera, K.; Ng, H.; Gabrielsson, L.; Salomonsson, A.-; Hanke, L.; Murrell, B.; et al. SARS-CoV-2 exposure, symptoms and seroprevalence in healthcare workers in sweden. Nat. Commun. 2020, 11, 5064. [CrossRef]

17. Houlihan, C.F.; Vora, N.; Byrne, T.; Lewer, D.; Kelly, G.; Heaney, J.; Gandhi, S.; Spyer, M.J.; Beale, R.; Cherepanov, P.; et al. Crick COVID-19 Consortium, SAFER Investigators. Pandemic peak SARS-CoV-2 infection and seroconversion rates in london frontline health-care workers. Lancet 2020, 396, e6-e7. [CrossRef]

18. Moscola, J.; Sembajwe, G.; Jarrett, M.; Farber, B.; Chang, T.; McGinn, T.; Davidson, K.W. Prevalence of SARS-CoV-2 antibodies in health care personnel in the New York city area. JAMA 2020, 324, 893-895. [CrossRef] [PubMed]

19. Stubblefield, W.; Talbot, H.; Feldstein, L. Seroprevalence of SARS-CoV-2 among frontline healthcare personnel during the first month of caring for COVID-19 patients-nashville, tennessee. Clin. Infect. Dis. 2020, ciaa936. [CrossRef] [PubMed]

20. Flaxman, S.; Mishra, S.; Gandy, A.; Unwin, H.J.T.; Mellan, T.A.; Coupland, H.; Whittaker, C.; Zhu, H.; Berah, T.; Eaton, J.W.; et al. Imperial College COVID-19 Response Team. Estimating the effects of non-pharmaceutical interventions on COVID-19 in europe. Nature 2020, 584, 257-261. [CrossRef]

21. Sheila, F.L.; Jia, W.; Denise, O.; Nicole, E.S.; Philippa, C.M.; Alison, H.; Stephanie, B.H.; Brian, D.M.; Stuart, C.; Tim, J.; et al. Oxford University Hospitals Staff Testing Group, The duration, dynamics and determinants of SARS-CoV-2 antibody responses in individual healthcare workers. Clin. Infect. Dis. 2021, ciab004. [CrossRef]

22. Wang, X.; Ferro, E.G.; Zhou, G.; Hashimoto, D.; Bhatt, D.L. Association between universal masking in a health care system and SARS-CoV-2 positivity among health care workers. JAMA 2020, 324, 703-704. [CrossRef]

23. Cirrincione, L.; Plescia, F.; Ledda, C.; Rapisarda, V.; Martorana, D.; Moldovan, R.E.; Theodoridou, K.; Cannizzaro, E. COVID-19 pandemic: Prevention and protection measures to be adopted at the workplace. Sustainability 2020, 12, 3603. [CrossRef]

24. Arons, M.M.; Hatfield, K.M.; Reddy, S.C.; Kimball, A.; James, A.; Jacobs, J.R.; Taylor, J.; Spicer, K.; Bardossy, A.C.; Oakley, L.P.; et al. Presymptomatic SARS-CoV-2 infections and transmission in a skilled nursing facility. N. Engl. J. Med. 2020, 382, $2081-2090$. [CrossRef]

25. Rapporto ISS COVID-19 n. 12/2020-Indicazioni ad Interim per Servizi Assistenziali di Telemedicina Durante L'Emergenza Sanitaria COVID-19 (Italian National Institute of Health (ISS), COVID-19 Report n. 12/2020-Interim Indications for Telemedicine Assistance Services during the COVID-19 Health Emergency). Available online: https://www.iss.it/documents/20126/0/ Rapporto+ISS+COVID-19+n.+12_2020+telemedicina.pdf/387420ca-0b5d-ab65-b60d-9fa426d2b2c7?t=1587107170414 (accessed on 9 January 2021).

26. Ramaci, T.; Barattucci, M.; Ledda, C.; Rapisarda, V. Social stigma during COVID-19 and its impact on HCWs outcomes. Sustainability 2020, 12, 3834. [CrossRef]

27. Marchesi, F.; Valente, M.; Riccò, M.; Rottoli, M.; Baldini, E.; Mecheri, F.; Bonilauri, S.; Boschi, S.; Bernante, P.; Sciannamea, A.; et al. Effects of bariatric surgery on COVID-19: A multicentric study from a high incidence area. Obes Surg. 2021. [CrossRef] 